Research Article

\title{
Application of SHEPWM in Helicopter Transient Electromagnetic Based on the Subsection Control Approach
}

\author{
Lihui Gao ${ }^{D},{ }^{1}$ Shengbao Yu, ${ }^{2}$ Chunxia Jiang ${ }^{D},{ }^{1}$ Nan Chen, ${ }^{1}$ Renhui Chen, ${ }^{1}$ \\ and Yong Huang \\ ${ }^{1}$ College of Electrical and Electronic Engineering, Changchun University of Technology, Changchun 130012, China \\ ${ }^{2}$ College of Instrumentation and Electrical Engineering, Jilin University, Changchun 130061, China \\ ${ }^{3}$ Company of Jilin Province BoAn Fire Fighting Equipment, Changchun 130026, China
}

Correspondence should be addressed to Chunxia Jiang; jiang_chunxia@163.com

Received 28 December 2020; Revised 6 February 2021; Accepted 27 February 2021; Published 9 March 2021

Academic Editor: Qiuye Sun

Copyright (c) 2021 Lihui Gao et al. This is an open access article distributed under the Creative Commons Attribution License, which permits unrestricted use, distribution, and reproduction in any medium, provided the original work is properly cited.

Guaranteeing the quality of the transmitting current under low switching frequency conditions is the crucial point in the helicopter transient electromagnetic (HTEM) system which affects the efficiency and exploration accuracy. HTEM requires high efficiency and low switching loss of the inverter power supply due to the facts that HTEM uses air-launched and air-received measurement methods, and the power storage capacity of the airborne transmitting system is limited. Paradoxically, low switching frequency directly affects the transmitting waveform quality and thereby affects the detection accuracy. In this study, we present a semiperiodic mirror symmetry selective harmonic elimination pulse width modulation (SHEPWM) based on the subsection control approach to balance transmitting current quality and switching loss. In the SHEPWM method, the semiperiodic mirror symmetry SHEPWM nonlinear equations are established by the time frequency domain information of the inverter output voltage and resolved by the artificial neural network (ANN) algorithm to attain switching time sequence of desired transmitting current. The simulation and experimental results verify the effectiveness of the SHEPWM subsection control strategy, which can reduce the switching loss while ensuring the current waveform quality and detection accuracy.

\section{Introduction}

Helicopter transient electromagnetic (HTEM) system is an efficient measurement tool applied in natural resource exploration, urban construction, and substation grounding grid diagnosis [1-3]. A typical HTEM system is composed of a transmitter and receiver, as shown in Figure 1. The transmitting coil transmits the high bipolar periodic current that can produce a primary magnetic field, which radiates in the form of smoke rings [4]. At an on-time period, a large periodic primary magnetic field induces the eddy current of the underground medium. At an off-time period, the coil sensor induces an exponential decay signal from the eddy current of the underground medium and then stores the received data. The underground objects with different resistivity induce magnetic fields in different values. Thus, different underground bodies will be identified after the processing of the recorded data.
The HTEM system uses air-launched and air-received measurement methods to detect the conductivity structure information within a few hundred meters of underground, and it needs the inverter which should have the conversion efficiency as high as possible in order to improve the cruising range. At present, a pulse width modulation (PWM) inverter is widely used in the main loop of the HTEM transmission system to obtain bipolar trapezoidal wave transmitting current. Obviously, in this system dominated by a power electronic converter, the cruising range of the HTEM system depends on the conversion efficiency of the PWM inverter. In recent years, the conversion efficiency of the PWM inverter has caused extensive research studies and achieved a corresponding development [5]. Generally, when the inverter of the HTEM transmission system is under the PWM control mode, the switching loss of the power device is proportional to the switching frequency. As the switching loss increases, the volume and weight of the heat sink will 


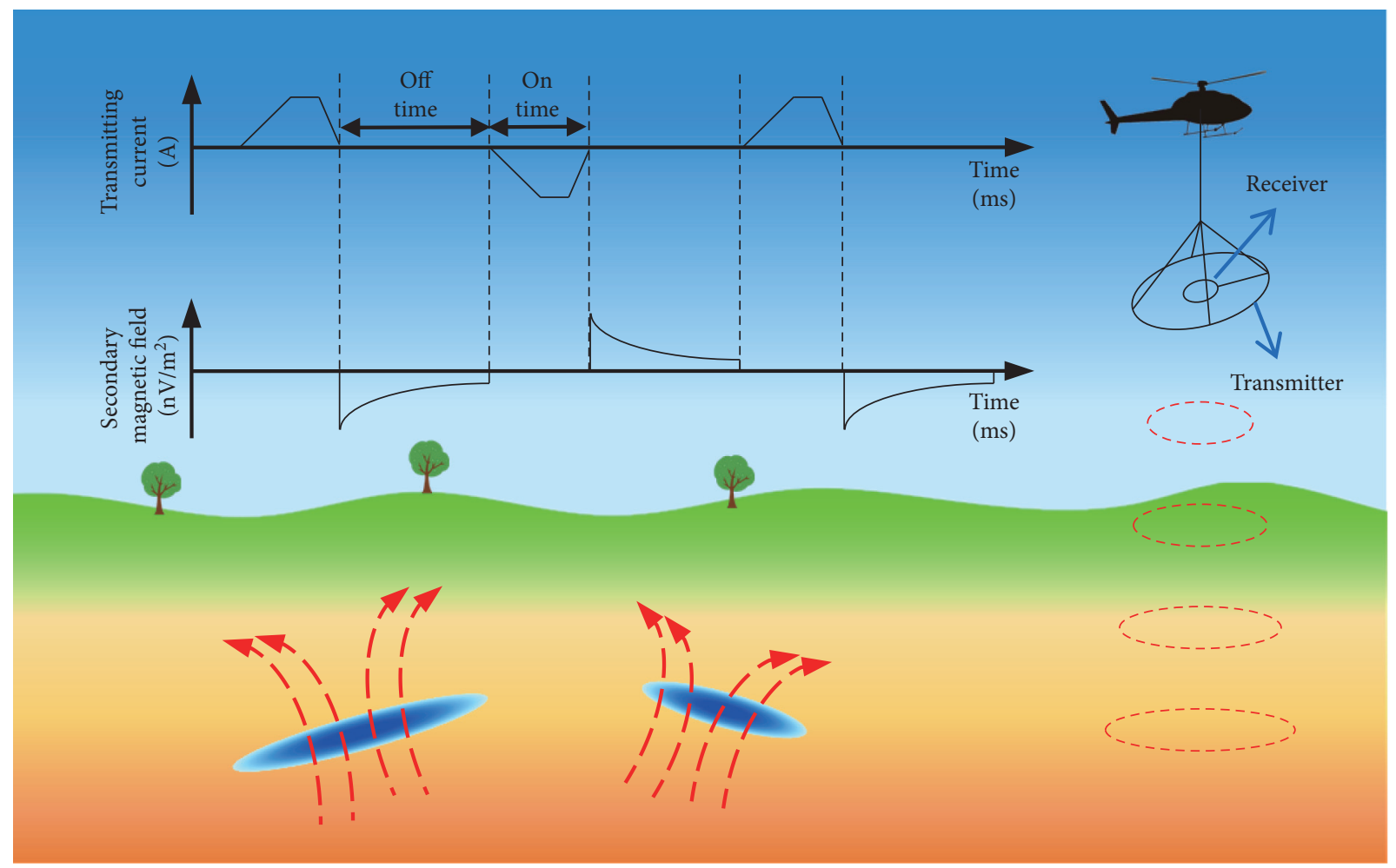

FIgURe 1: A typical HTEM system.

increase, and the efficiency of the system will reduce. However, the low switching frequency directly affects the transmitting waveform quality and thereby affects the detection accuracy. That is because the geophysical effect of HTEM is closely related to the quality of the bipolar trapezoidal wave transmitting current; the better the stability of the current waveform at the flat top and the smaller the reverse overshoot along the descending edge, the better the exploration effect.

In view of above questions, this study proposes a semiperiodic mirror symmetry selective harmonic elimination pulse width modulation (SHEPWM) based on a subsection control approach to balance transmitting current quality and switching loss. In the SHEPWM method, the left polynomial of the SHEPWM nonlinear equations is established by the time domain information of the transmitting voltage and the right polynomial of the SHEPWM nonlinear equations is established by the frequency domain information of the transmitting voltage. Afterwards, the semiperiod mirror-symmetric SHEPWM subsection control nonlinear equations are obtained, which can control the frequency domain characteristics (harmonic amplitude, harmonic phase, and DC component) of the transmitting voltage and time domain characteristics (rising edge, flat top, and descending edge) of the transmitting current. Finally, a desired output voltage and output current with lower switching frequency can be obtained by solving the switching angles of a ternary sequence with an artificial neural network (ANN) algorithm.

In the following sections, we first present the basic theory of SHEPWM nonlinear equations established by the HTEM voltage waveform. Then, we give a comparison of the HTEM transmitting current waveform via simulation under PWM and SHEPWM. In the end, the experimental results show that the SHEPWM strategy can efficiently reduce the switching frequency under the unchanged output waveform quality.

\section{The Principle of HTEM SHEPWM}

2.1. Establishment of HTEM SHEPWM Nonlinear Equations. SHEPWM is an important technique for controlling the harmonics in the output voltage waveform of inverters, which offers several advantages including superior performance with low switching frequency, more controlled loworder harmonic of output waveform, and capability of avoiding tripled harmonics. All the above benefits enable SHEPWM to replace other modulation methods in some areas, such as ground power units [6], variable speed drives $[7,8]$, dual-frequency induction heating [9], and a multilevel inverter [10]. Since the output waveform of the SHEPWM technique mentioned above is sinusoidal, the output voltage waveforms are usually set to have quarter symmetry, and all the harmonics and DC component are set to zero [11, 12]. However, the transmitting current of HTEM is a bipolar trapezoidal wave with semiperiodic mirror symmetry. Therefore, the semiperiodic mirror symmetry SHEPWM based on the subsection control approach is proposed to enhance useful odd harmonic components and eliminate unnecessary even harmonic components in our study.

The output current and output voltage of the HTEM inverter in one cycle are shown in Figures 2(a) and 2(b). In 


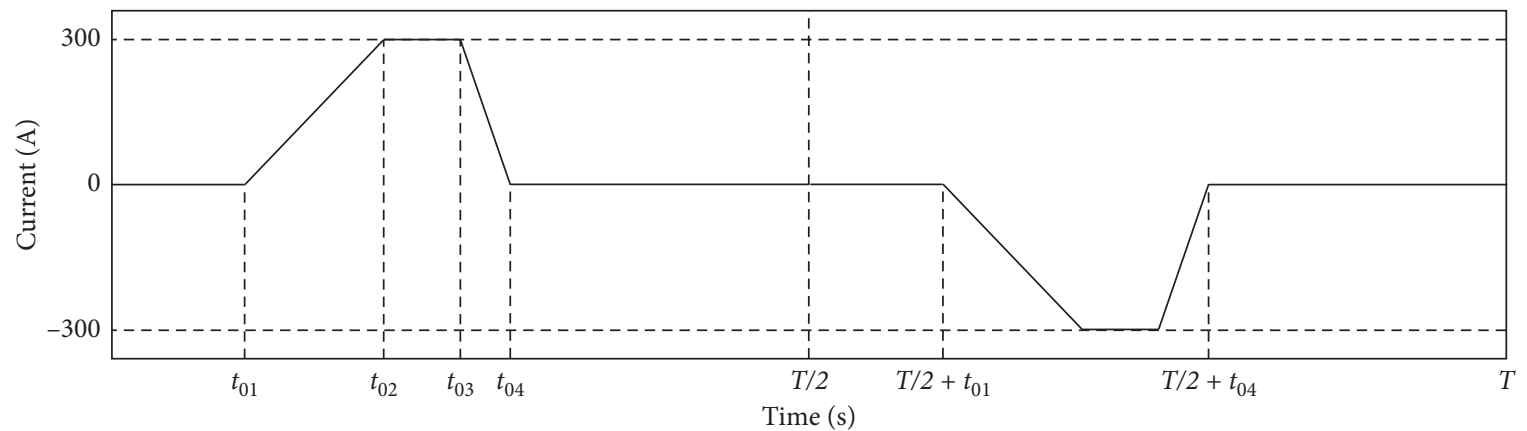

(a)

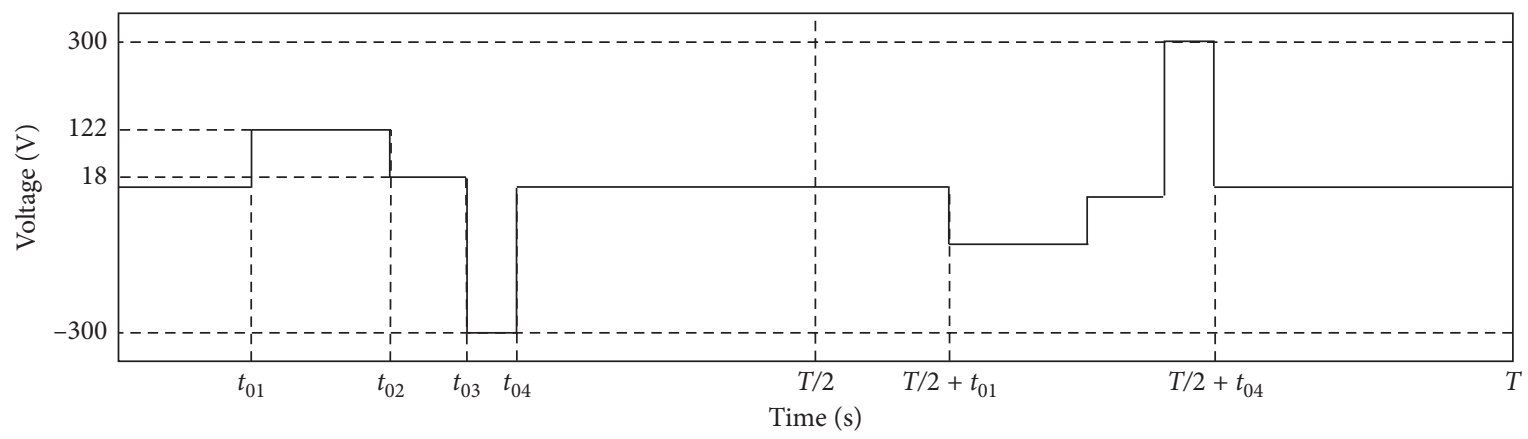

(b)

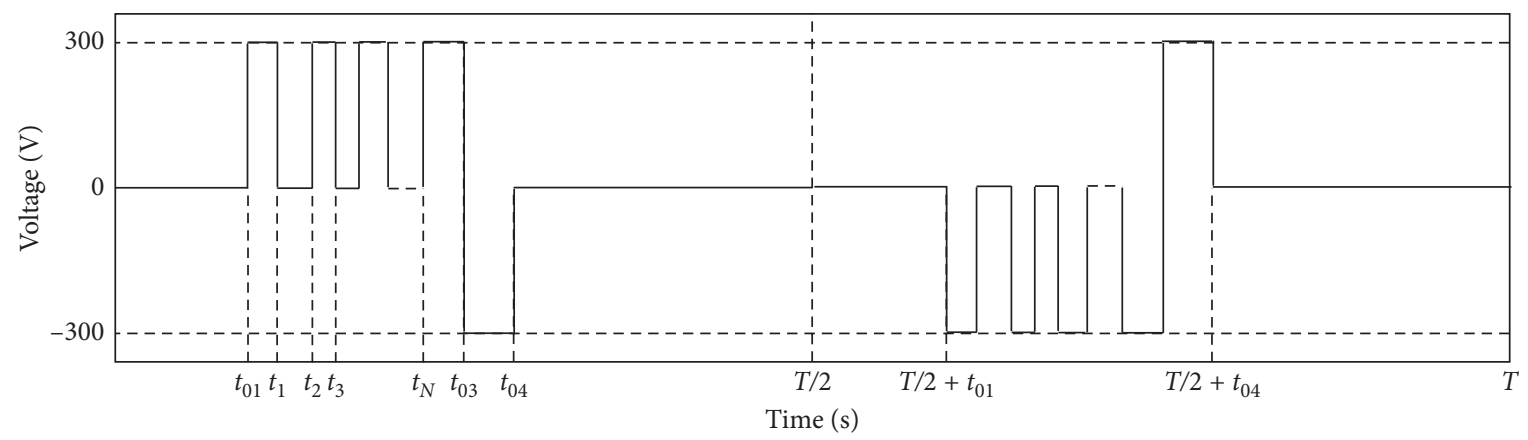

(c)

FIGURE 2: Application of SHEPWM strategy in HTEM. (a) HTEM outputs current waveform, (b) HTEM outputs voltage waveform, and (c) SHEPWM waveform.

the stages of $0 \sim t_{01}, t_{04} \sim T / 2+t_{01}$, and $T / 2+t_{04} \sim T$, the output current and output voltage are zero, where $t_{01}=3.8 \mathrm{~ms}, t_{02}=7.8 \mathrm{~ms}, t_{03}=10 \mathrm{~ms}, t_{04}=11.43 \mathrm{~ms}$, and $T=40 \mathrm{~ms}$. The corresponding unipolar SHEPWM pulse waveform is shown in Figure 2(c). The DC side voltage of the inverter $U_{d}$ is $300 \mathrm{~V},\left(t_{1}, t_{2}, \cdots, t_{\mathrm{N}}\right)$ is the switching instants to be determined, and $N$ is the total number of switching angles in half cycle. According to the time domain characteristics of the output voltage waveform, a SHEPWM pulse waveform has semiperiodic mirror symmetry. Meanwhile, there is no pulse voltage at the stages of $0 \sim t_{01}, t_{04} \sim T / 2+t_{01}$, and $T / 2+t_{04} \sim T$ and low level at the stages of $t_{03} \sim t_{04}$.

According to the basic properties of Fourier series, a periodic waveform can be expressed as a superposition of the DC component, fundamental component, and harmonic components:

$$
y(t)=\frac{a_{0}}{2}+\sum_{i=1}^{\infty}\left[a_{i} \sin (i \omega t)+b_{i} \cos (i \omega t)\right], \quad i=1,2,3 \ldots,
$$

where $i$ is the number of harmonics, $a_{0} / 2$ is the DC component, $a_{i}$ and $b_{i}$ are the Fourier coefficients, and $\omega=2 \pi f$ is the angular frequency. $a_{0}, a_{i}$, and $b_{i}$ can be obtained from integral (2),

$$
\left\{\begin{array}{l}
a_{i}=\frac{2}{T} \int_{0}^{T} y(t) \sin (i \omega t) d t \\
b_{i}=\frac{2}{T} \int_{0}^{T} y(t) \cos (i \omega t) d t, \quad i=1,2,3 \ldots \\
a_{0}=\frac{2}{T} \int_{0}^{T} y(t) d t
\end{array}\right.
$$


Based on formula (2), the expression of the Fourier coefficients $a_{u i}$ and $b_{u i}$ of the HTEM output voltage waveform in Figure 2(b) is obtained, as shown in equation (3). The frequency domain characteristics of the HTEM output voltage waveform are shown in Figure 3. Due to the symmetrical characteristics of the waveform in Figure 2(b), the DC component and even harmonics in Figure 3 are all zero. Moreover, the frequency domain information weakens with the increase of harmonic frequency. Therefore, the output waveform which is infinitely closer to the optimal effect can be fitted by a finite number of frequency domain information.

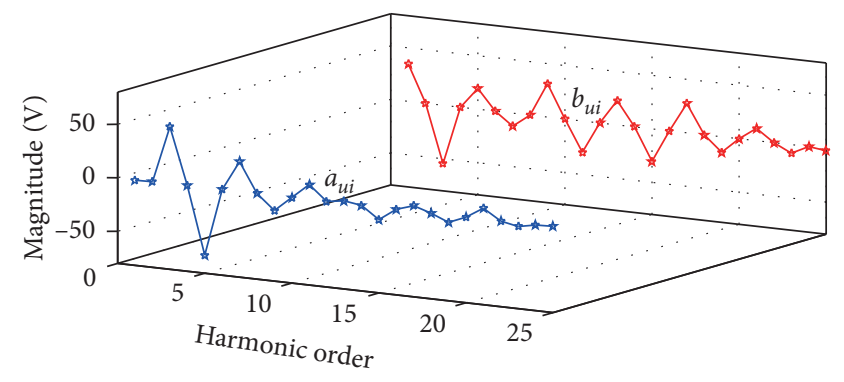

FIgURE 3: The frequency domain characteristics of the HTEM output voltage waveform.

$$
\left\{\begin{array}{l}
a_{u i}=\frac{300}{\pi i}\left[\begin{array}{c}
0.41 \cos (0.19 \pi i)-0.35 \cos (0.39 \pi i)-1.06 \cos (0.5 \pi i)+\cos (0.5715 \pi i)- \\
0.41 \cos (1.19 \pi i)+0.35 \cos (1.39 \pi i)+1.06 \cos (1.5 \pi i)-\cos (1.5715 \pi i)
\end{array}\right] \\
b_{u i}=\frac{300}{\pi i}\left[\begin{array}{c}
-0.41 \sin (0.19 \pi i)+0.35 \sin (0.39 \pi i)+1.06 \sin (0.5 \pi i)-\sin (0.5715 \pi i)+ \\
0.41 \sin (1.19 \pi i)-0.35 \sin (1.39 \pi i)-1.06 \sin (1.5 \pi i)+\sin (1.5715 \pi i)
\end{array}\right] \quad i=1,3,5 \ldots
\end{array}\right.
$$

Also based on formula (2), the expression of the Fourier coefficients $a_{s i}$ and $b_{s i}$ of the SHEPWM waveform in Figure 2(c) is obtained, as shown in equation (4). By setting $N=16$ and the switching time sequence $t_{1}, t_{2}, \ldots, t_{16}$ on average, the frequency domain information about the corresponding SHEPWM waveform can be obtained, as shown in Figure 4. Observing the frequency domain information of the waveform, the DC component and even harmonics are all zeros, while the amplitude of the odd harmonic components depends on the switching time sequence. Therefore, by adjusting the switching time sequence, a finite number of frequency domain information about the SHEPWM waveform and HTEM output voltage waveform can be matched, and then, the time domain waveform which is infinitely closer to the optimal effect can be fitted out.

$$
\left\{\begin{array}{l}
a_{s i}=\frac{2 U_{d}}{i \pi}\left[\cos \left(i \omega t_{01}\right)+\sum_{k=1}^{N}(-1)^{k} \cos \left(i \omega t_{k}\right)-2 \cos \left(i \omega t_{03}\right)+\cos \left(i \omega t_{04}\right)\right] \\
b_{s i}=\frac{2 U_{d}}{i \pi}\left[-\sin \left(i \omega t_{01}\right)-\sum_{k=1}^{N}(-1)^{k} \sin \left(i \omega t_{k}\right)+2 \sin \left(i \omega t_{03}\right)-\sin \left(i \omega t_{04}\right)\right] \quad i=1,3,5 \ldots
\end{array}\right.
$$

Based on the above analysis, the mathematical model of HTEM SHEPWM can be established:

$$
\left\{\begin{array}{l}
\frac{2 U_{d}}{i \pi}\left[\cos \left(i \omega t_{01}\right)+\sum_{k=1}^{N}(-1)^{k} \cos \left(i \omega t_{k}\right)-2 \cos \left(i \omega t_{03}\right)+\cos \left(i \omega t_{04}\right)\right]=a_{u i} \\
\frac{2 U_{d}}{i \pi}\left[-\sin \left(i \omega t_{01}\right)+\sum_{k=1}^{N}(-1)^{k+1} \sin \left(i \omega t_{k}\right)+2 \sin \left(i \omega t_{03}\right)-\sin \left(i \omega t_{04}\right)\right]=b_{u i} \quad i=1,3,5 \ldots
\end{array} .\right.
$$

Equation (5) has $N$ degrees of freedom if the switching instants are independent of each other. In calculation, each odd harmonic component requires two degrees of freedom $(N=2)$ to control because it contains amplitude and phase 


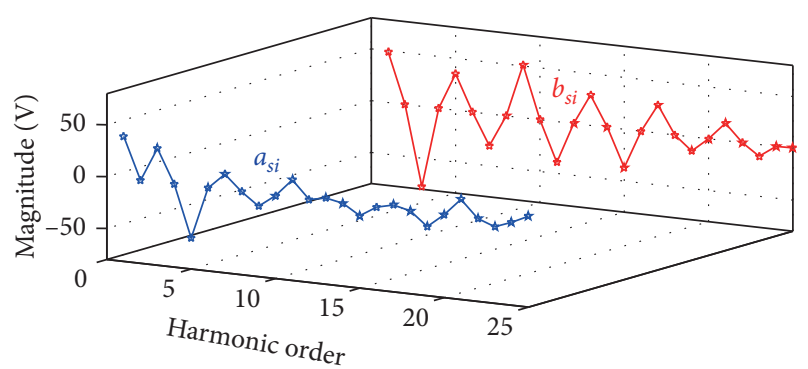

Figure 4: The frequency domain characteristics of the SHEPWM waveform.

information. All even harmonics and DC component are zeros, and no degree of freedom is required to control. Therefore, (5) can control the first $N$ harmonics of the output waveform. In addition, the switching angles calculated using (5) must satisfy the following relationship:

$$
t_{01}<t_{1}<t_{2}<\cdots<t_{N}<t_{03} .
$$

\subsection{Application of the ANN to Solute HTEM SHEPWM} Nonlinear Equations. Usually, the SHEPWM nonlinear equations are solved by two approaches. In the first approach, numerical iterative techniques such as Newton-Raphson $[13,14]$ and Gauss-Newton are proposed. However, these methods require the selection of initial point which must be very close to the exact solution or will lead to the solution which does not converge. The second approach overcomes the drawbacks, and it is used to find the global optimum solution with a short time searching. This approach employs analytical equations to form an objective function, which is then minimized to get the solutions. Grasshopper optimization algorithm [15], genetic algorithm [16], bee algorithm [17], and Hopfield neural network [18] have been adopted for minimizing the objective function. In our study, we use the second approach and solve the equations by using an artificial neural network (ANN) algorithm. Compared with NewtonRaphson in the first approach, the ANN is not fully dependent on the initial guesses, and it is also easy to understand and simple to program on personal computers using Matlab [19].

The following section explains the use of the ANN algorithm to solve (5). Equation (5) is rewritten into the following form:

$$
\left\{\begin{array}{l}
f_{1}\left(\alpha_{1}, \alpha_{2}, \ldots, \alpha_{n}\right)=P_{1} \\
f_{2}\left(\alpha_{1}, \alpha_{2}, \ldots, \alpha_{n}\right)=P_{2} \\
\vdots \\
f_{n}\left(\alpha_{1}, \alpha_{2}, \ldots, \alpha_{n}\right)=P_{n}
\end{array}\right.
$$

where $f_{n}(\cdot)$ is a function of variables, $\left(\alpha_{1}, \alpha_{2}, \ldots, \alpha_{n}\right) \in \Re$, and $P_{n}$ is the real constant calculated by the frequency domain information of the output voltage.

Define the energy function of equation (7) as

$$
E=\frac{1}{2}\|G(\alpha)\|_{2}^{2},
$$

where

$$
\begin{aligned}
G(\alpha) & =\left[g_{1}(\alpha), g_{2}(\alpha), \ldots, g_{n}(\alpha)\right]^{T}, \\
\alpha & =\left(\alpha_{1}, \alpha_{2}, \ldots, \alpha_{n}\right), \\
g_{n}(\alpha) & =f_{n}\left(\alpha_{1}, \alpha_{2}, \ldots, \alpha_{n}\right)-P_{n} .
\end{aligned}
$$

Obviously, when the solution of the nonlinear equation (7) is $\alpha^{*}$, the minimum point of the energy function (8) is also $\alpha^{*}$. Introducing formula (8), the analytical problem is transformed into an optimization problem for solving the minimum value of the energy function, so that the following neural network model can be established:

$$
\left\{\begin{array}{l}
\frac{d \alpha}{d t}=-W \nabla E(\alpha), \\
\alpha(t+\Delta t)=\alpha-\Delta t W \nabla E(\alpha),
\end{array}\right.
$$

where

$$
\nabla E(\alpha)=G^{\prime}(\alpha)^{T} G(\alpha),
$$

where $\boldsymbol{W}=\left(w_{\mathrm{ij}}\right)_{\mathrm{nn}}$ is the positive definite matrix, $\nabla E(\alpha)$ is the gradient of the energy function (10), and $\Delta t$ is the step size, which is usually a small decimal fraction, such as 0.0001 .

Let $H(\alpha)=\nabla E(\alpha)=\left[h_{1}(\alpha), h_{2}(\alpha), \ldots, h_{n}(\alpha)\right]^{T}$, a single layer feedback ANN for (16) is obtained, as shown in Figure 5 . The network has $n$ neurons, which are connected from left to right by transferring function $H(\alpha)$, synaptic weights $\left(w_{\mathrm{ij}}\right)_{\mathrm{nn}}$, and integral activation function $\int$. Besides, with the feedback structure, $\alpha$ is both the input and output vector for the network, and the initial value of $\alpha$ is $\alpha^{\mathbf{0}}=\left(\alpha_{1}{ }^{\mathbf{0}}, \alpha_{2}{ }^{\mathbf{0}}, \cdots, \alpha_{n}{ }^{\mathbf{0}}\right)=\omega t^{\mathbf{0}}=\omega\left(t_{1}{ }^{\mathbf{0}}, t_{2}{ }^{\mathbf{0}}, \cdots \cdot, t_{N} \mathbf{0}\right)$, where $t^{\mathbf{0}}$ is set arbitrarily under the restriction of (6). When searching for the optimum solution, the value $\alpha$ is updated constantly by using a cyclic iterative algorithm until the energy function converges to the convergence precision $\varepsilon$, which is a minuteness number larger than 0 . When the energy function is less or equal to $\varepsilon$, the update process ends. Thus, the SHEPWM nonlinear equations is solved and the optimal solution of $\alpha$ is searched. The flowchart of the solution process for the ANN is shown in Figure 6.

\section{Simulation Result}

In order to evaluate the performance of the semiperiodic mirror symmetry SHEPWM based on the subsection control approach, computer simulations have been performed using Matlab/Simulink. The simulation diagram is shown in Figure 7. The simulation parameters are as follows: DC voltage $300 \mathrm{~V}$, load resistance $0.06 \Omega$, load inductance $1.5 \mathrm{mH}$, and output current frequency $25 \mathrm{~Hz}$. A full-bridge topology has been formed using four IGBTs. The switching signals are derived from the switching subsystem. The switching instants of the PWM strategy is obtained by comparing the controlled voltage waveform with triangle carrier, and the switching instants of the SHEPWM strategy are obtained by solving equation (5) with the ANN. Since PWM is extensively employed in HTEM, a detailed 


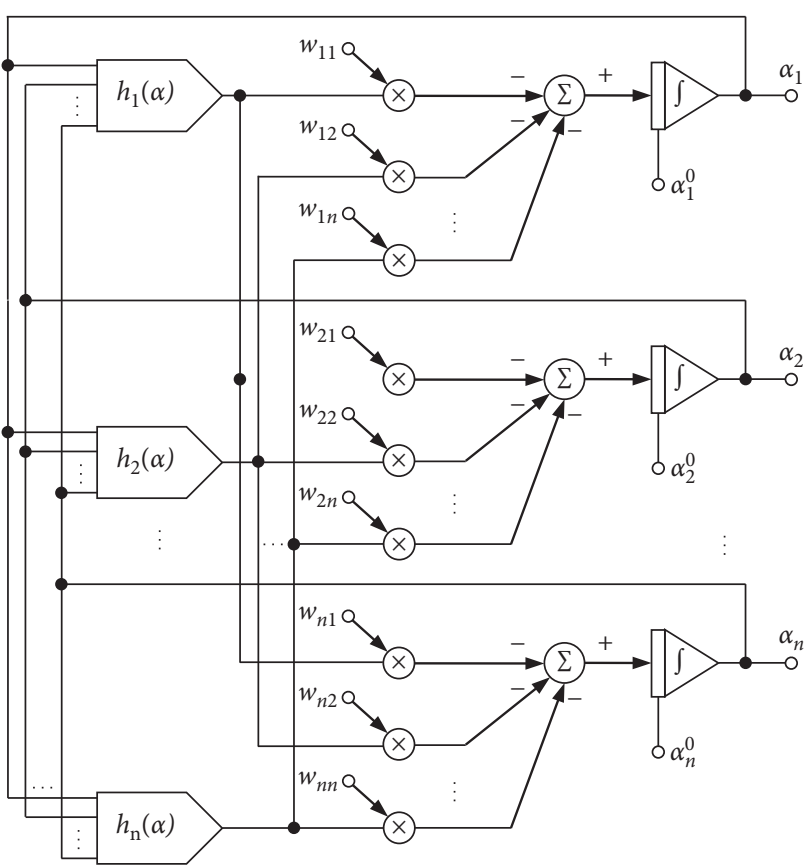

FIgURE 5: Diagram of the ANN for equation (10).

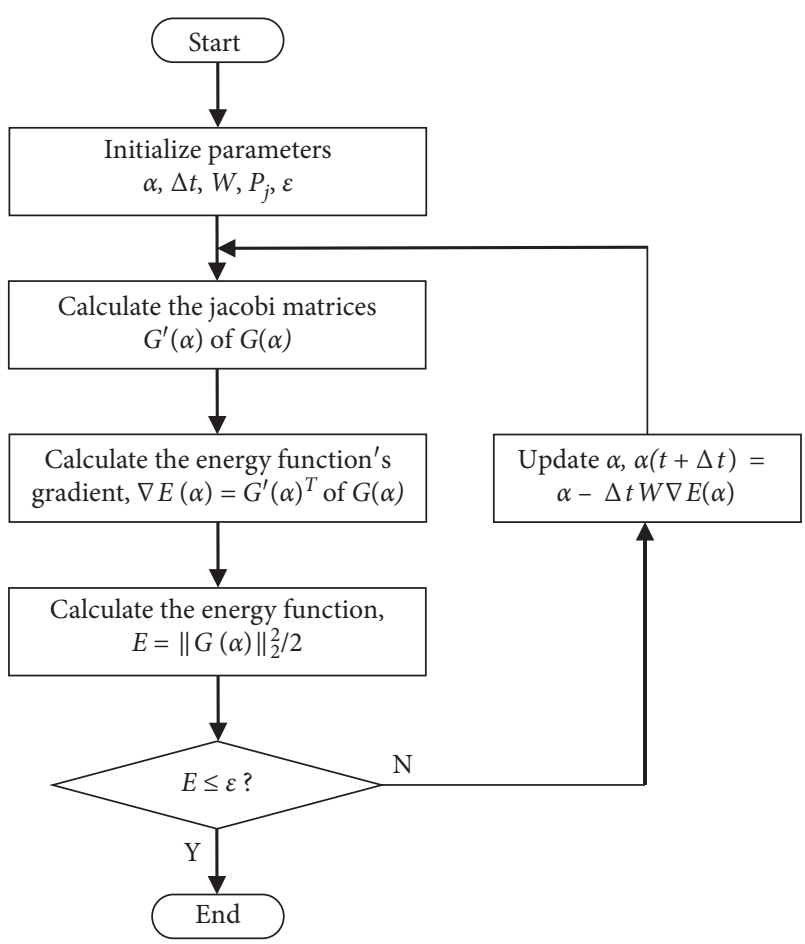

Figure 6: Flowchart of the solution process for the ANN.

comparative study of output waveform under SHEPWM and PWM is carried out.

Figure 8 shows the simulation results of the transmitting current reverse overshoot with the number of switching times under two control strategies. With the increase of switching times, the reverse overshoot of the transmitting current under PWM strategy decreases gradually. The

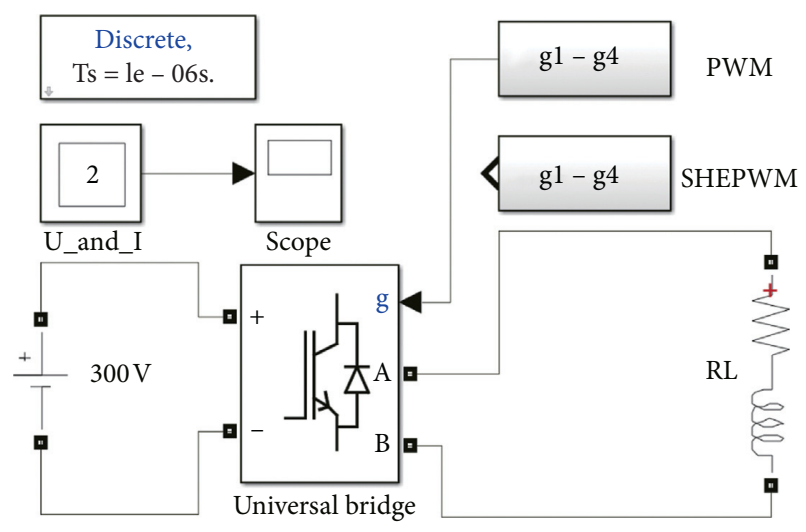

Figure 7: Simulation diagram of the proposed system.

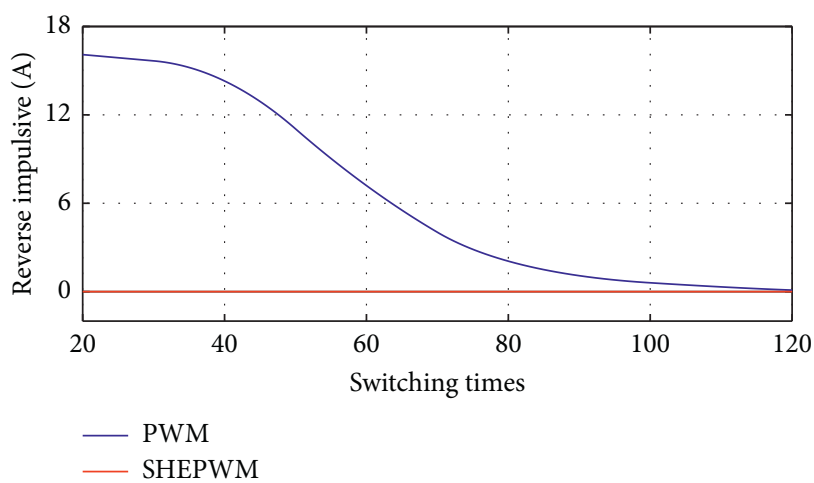

FIGURE 8: Simulation result of transmitting current reverse overshoot.

reverse overshoot falls to 0 when the number of switches in one cycle is 120 , which meets the quality requirement of transmitting waveform. However, the reverse overshoot of the transmitting current under SHEPWM strategy is identically zero without the limit of switching times.

Figure 9 shows the simulation results of the average value error for transmitting current at the flat top under two control strategies. Similar to the simulation results of the transmitting current reverse overshoot, the average value error of the transmitting current at the flat top under SHEPWM strategy is normally around $1 \%$ without the limit of switching times. However, in the PWM strategy, the average value error of the transmitting current at the flat top is closely related to the switching time and decreases as the switching time increases. When the switching time is greater than 120, the average value error of PWM strategy is equivalent to that of SHEPWM strategy, which meets the quality requirement of transmitting waveform.

The reason for this phenomenon can be explained that the PWM is a comparative method to fit the controlled waveform. When the switching times are too few, the fitting effect will be distorted. Although increasing the switching frequency can improve the control effect, this will increase the switching loss and reduce the conversion efficiency. The SHEPWM is a calculation method which accurately controls the power electronic device on-off time based on the 


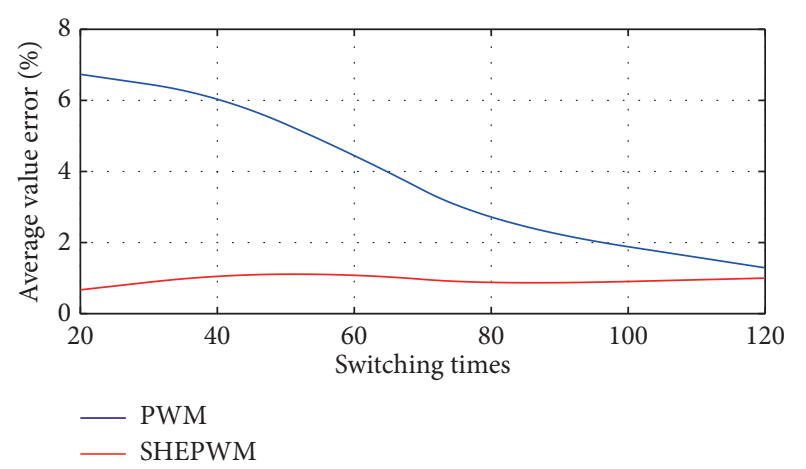

FIgURE 9: Simulation result of the average value error for transmitting current at the flat top.

modulation target's frequency and time domain and thus optimizes the output waveform. Therefore, under the same control effect, the switching frequency of the SHEPWM strategy is much lower, which can greatly reduce the switching loss and improve the conversion efficiency.

According to the analysis above, the PWM and SHEPWM simulation results with 40 and 120 switching instants in one cycle are given.

Figure 10 shows the simulation results of the PWM control strategy with switching frequency $1600 \mathrm{~Hz}$, and the voltage waveform has 40 switching instants in one cycle. Due to the low switching frequency, the output voltage occurs as oscillation at $11.43 \mathrm{~ms}$, the reverse overshoot of output current is $-15.24 \mathrm{~A}$, and the average value of output current at the flat top is $281.5 \mathrm{~A}$.

Figure 11 shows the simulation results of the PWM control strategy with switching frequency $4800 \mathrm{~Hz}$, and the voltage waveform has 120 switching instants in one cycle. The output voltage does not occur oscillation at $11.43 \mathrm{~ms}$; since the switching frequency increased 3 times, the reverse overshoot of output current is 0 , and the average value of output current at the flat top is $296.1 \mathrm{~A}$.

Figure 12 shows the simulation results of the SHEPWM control strategy with switching frequency $1600 \mathrm{~Hz}$, and the voltage waveform has 40 switching instants in one cycle. The switching time sequence is shown in Table 1 . The voltage and current waveform both have no overshoot and oscillation, and the average value of output current at the flat top is $303.3 \mathrm{~A}$

Figure 13 shows the local amplification of the simulation current waveform under PWM and SHEPWM control strategies. By comparing the output current quality, it can be obtained that SHEPWM (40) is stable at the flat top and there is no reverse overshoot at the descending edge. The output current quality of the SHEPWM (40) is comparable to that of the PWM (120), which is superior to the PWM (40). The result of the simulation is in accordance with the theory.

\section{Experimental Result}

The experimental device shown in Figure 14 is built to verify the feasibility of the SHEPWM control strategy. The

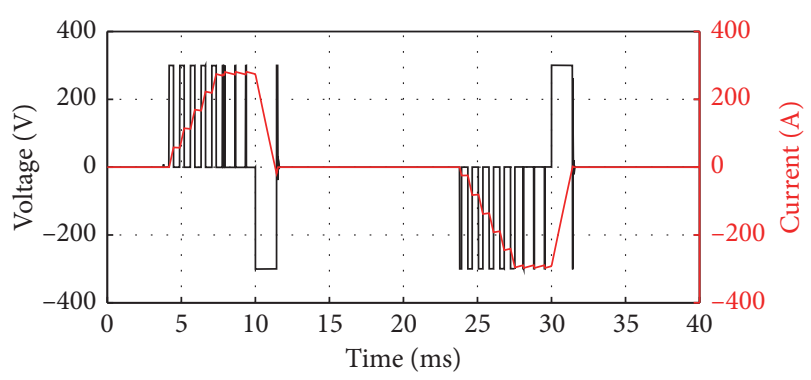

Figure 10: Simulation results based on PWM (40 instants).

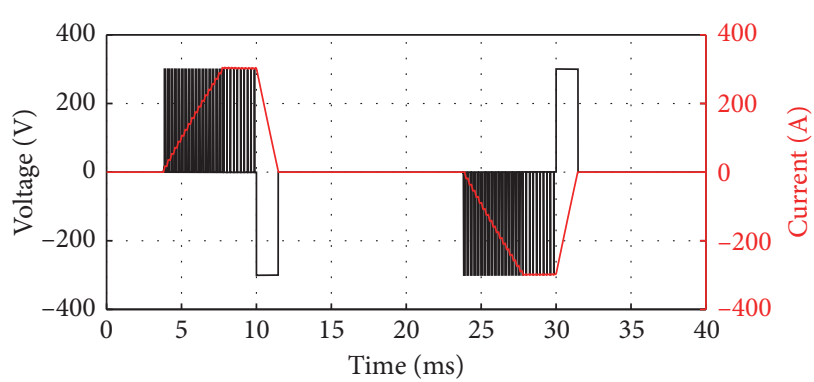

FIgURE 11: Simulation results based on PWM (120 instants).

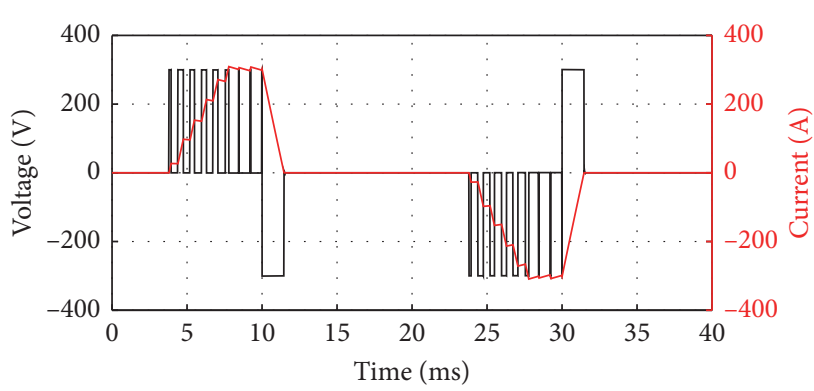

Figure 12: Simulation results based on SHEPWM (40 instants).

TABLE 1: Temperature and wildlife count in the three areas covered by the study.

\begin{tabular}{llrl}
\hline \multicolumn{4}{c}{ Switching angles (rad) } \\
\hline 0.6182059 & 0.6915617 & 0.7509558 & 0.8249359 \\
0.8719098 & 0.9481457 & 1.0021651 & 1.0720391 \\
1.1242280 & 1.2068875 & 1.2373634 & 1.3462110 \\
1.3512064 & 1.4749950 & 1.4830780 & 1.5687854 \\
\hline
\end{tabular}

experimental parameters are as follows: input DC voltage $10 \mathrm{~V}$, load resistance $0.06 \Omega$, and load inductance $1.5 \mathrm{mH}$. The FPGA EP3C25E144C8 manufactured by Altera is used as the main control chip. The IPM PM50B4LA060 is selected to use as the main switch component. The PWM control strategy with switching frequencies $1600 \mathrm{~Hz}$ and $4800 \mathrm{~Hz}$ and the corresponding voltage waveforms has 40 and 120 switching instants in one cycle, respectively. The SHEPWM controls strategy with switching frequency $1600 \mathrm{~Hz}$, the voltage waveform has 40 switching instants in one cycle, and the switching time sequence is shown in Table 1. 


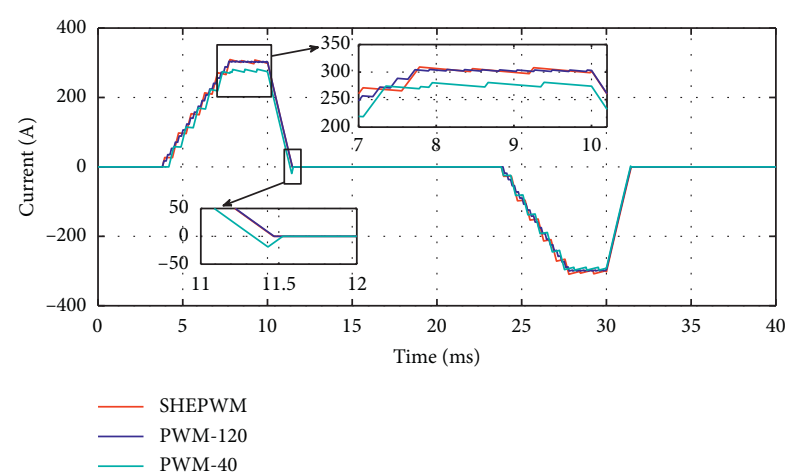

FIgURE 13: Local amplification of the simulation current.

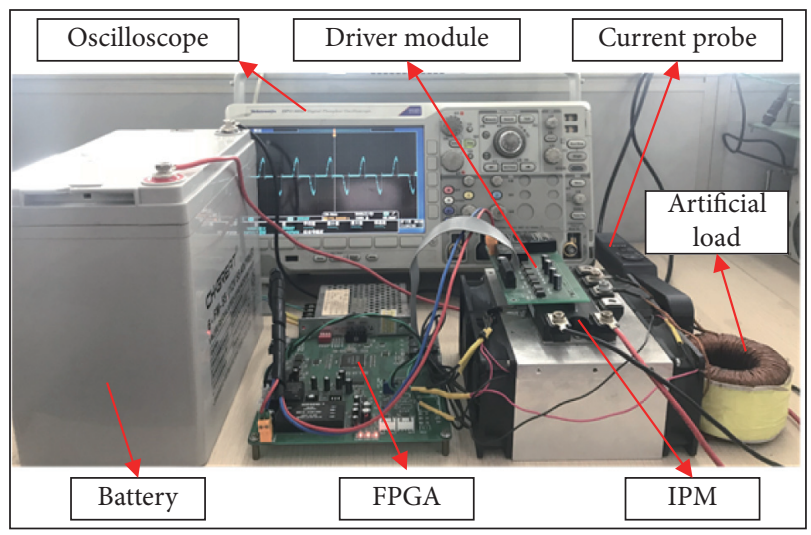

Figure 14: Experimental setup.

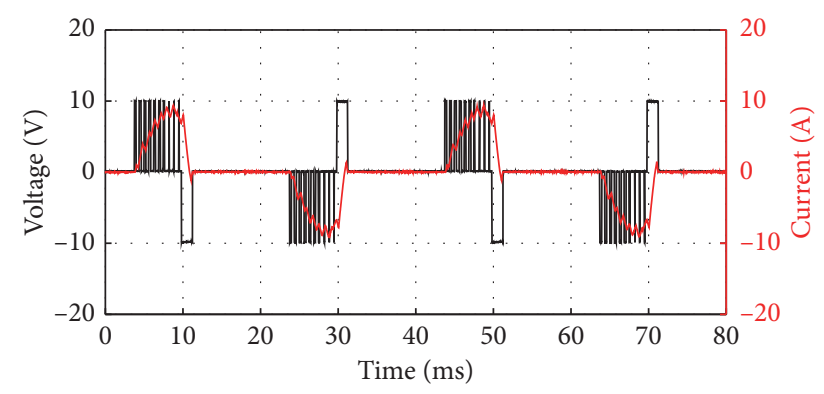

FIgURE 15: Experiment results based on PWM (40 instants).

Figure 15 shows the experiment results of the PWM control strategy with switching frequency $1600 \mathrm{~Hz}$. The output voltage is $10 \mathrm{~V}$, and the voltage waveform has 40 switching instants in one cycle. Due to the low switching frequency, the output current waveform flat top distortion, the average value of output current at the flat top is about $8.4 \mathrm{~A}$, and the reverse overshoot of output current is $-1.172 \mathrm{~A}$.

Figure 16 shows the experiment results of the PWM control strategy with switching frequency $4800 \mathrm{~Hz}$. The output voltage is $10 \mathrm{~V}$, and the voltage waveform has 120 switching instants in one cycle. With the increase of the switching frequency, the flat top of the output current waveform is stable, the average value of output current at the

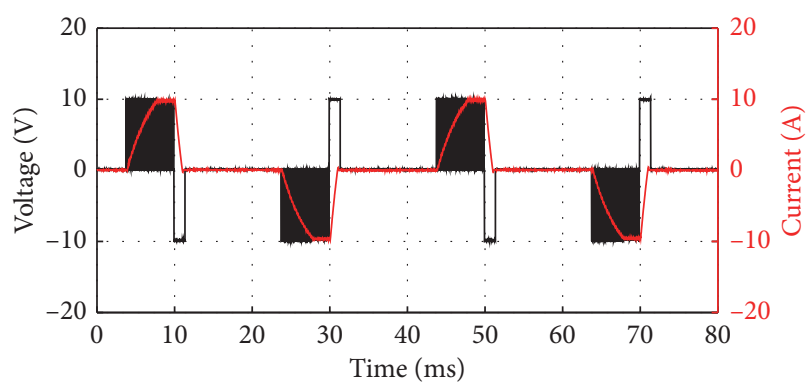

FIgURE 16: Experiment results based on PWM (120 instants).

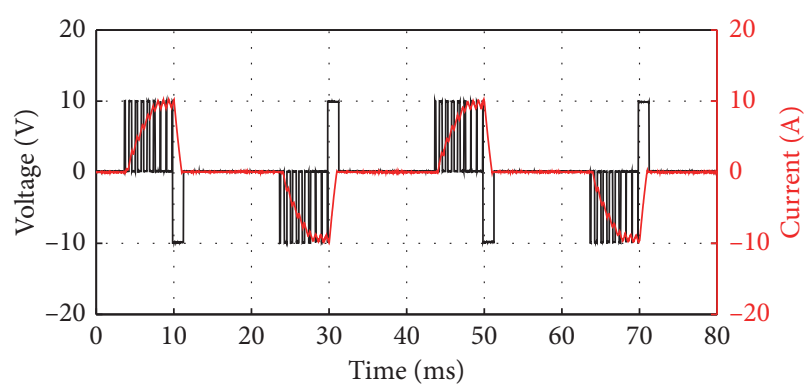

FIgURE 17: Experiment results based on SHEPWM (40 instants).

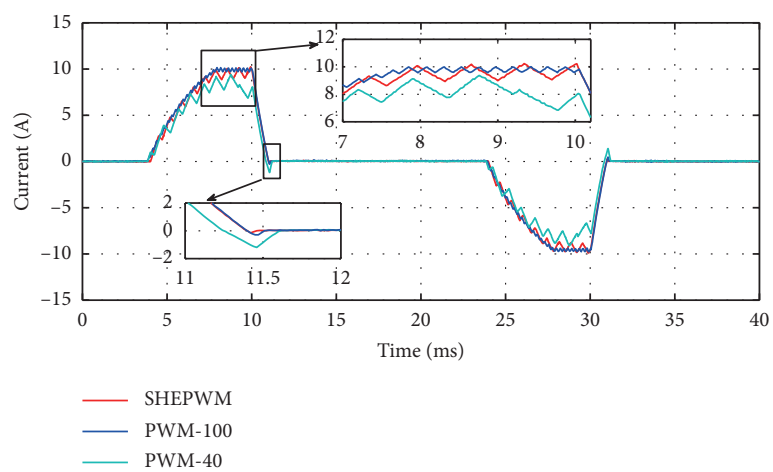

FIGURE 18: Local amplification of the experiment current.

flat top is about $9.8 \mathrm{~A}$, and the reverse overshoot of the output current is almost nonexistent.

Figure 17 shows the experiment results of the SHEPWM control strategy with switching frequency $1600 \mathrm{~Hz}$. The output voltage is $10 \mathrm{~V}$, and the voltage waveform has 40 switching instants in one cycle. It can be seen that, even under the condition of low switching frequency, the average value of output current at the flat top is maintained at about $9.5 \mathrm{~A}$, and there is no reverse overshoot.

Figure 18 shows the local amplification of the experiment current waveform under PWM and SHEPWM control strategies. The experiment verifies that, under the same switching frequency, the quality of the SHEPWM waveform is superior to the PWM. Under the same waveform quality, the switching loss of the SHEPWM inverter is one-third of the PWM inverter. The result of the experiment is accordant with the theory and simulation, verifying the effectiveness of the proposed method. 


\section{Conclusion}

In this study, a semiperiodic mirror symmetry SHEPWM based on the subsection control approach is proposed to balance transmitting current quality and switching loss in a HTEM system. SHEPWM control strategy first deduces the corresponding nonlinear equations according to the time frequency domain information of the inverter output voltage, employs the ANN algorithm to solve the power device switching instants, and finally obtains the switching instant sequence of desired transmitting current. Simulation and experimental results verify that the SHEPWM control strategy has the following advantages: in the case of the same inverter switching frequency, SHEPWM waveform quality is better than PWM; in the case of the same waveform quality, SHEPWM inverter switching frequency is one-third of PWM.

\section{Data Availability}

The ANN program, Matlab/Simulink model, and XLSX data used to support the findings of this study are available from the corresponding author upon request.

\section{Conflicts of Interest}

The authors declare that they have no conflicts of interest.

\section{Acknowledgments}

The authors would like to thank the editors and reviewers for their time and advice. This work was supported by the "Development of Helicopter Aeroelectromagnetic Measurement Technology System" (National Key R\&D Program of China, grant no. 2017YFC0601802).

\section{References}

[1] A. K. Mohamed, M. A. Meju, and S. L. Fontes, "Deep structure of the northeastern margin of the Parnaiba Basin, Brazil, from magnetotelluric imaging," Geophysical Prospecting, vol. 50, no. 6 , pp. 589-602, 2002.

[2] Y. Shengbao, D. Guanliang, L. Nannan et al., "Diagnosis for conductor breaks of grounding grids based on the wire loop method of the transient electromagnetic method," Mathematical Problems in Engineering, vol. 2019, Article ID 1489543, 11 pages, 2019.

[3] C. Yu, Z. Fu, G. Wu, L. Zhou, X. Zhu, and M. Bao, "Configuration detection of substation grounding grid using transient electromagnetic method," IEEE Transactions On Industrial Electronics, vol. 64, no. 8, pp. 6475-6483, 2017.

[4] M. N. Nabighian, Electromagnetic Methods in Applied Geophysics: 640 Application Parts $A$ and B, Vol. 2, Society of Exploration Geophysicists, Tulsa, OK, USA, 1991.

[5] R. Wang, Q. Y. Sun, P. J. Zhang, Y. H. Gui, D. H. Qin, and P. Wang, "Reduced-order transfer function model of the droop-controlled inverter via Jordan continued-fraction expansion," IEEE Transactions On Energy Conversion, vol. 35, no. 3, pp. 1585-1595, 2020.

[6] U. B. Jensen, F. Blaabjerg, and J. K. Pedersen, "A new control method for $400-\mathrm{Hz}$ ground power units for airplanes," IEEE
Transactions on Industry Applications, vol. 36, no. 1, pp. 180-187, 2000.

[7] S. R. Bowes, "Advanced regular-sampled PWM control techniques for drives and static power converters," IEEE Transactions on Industrial Electronics, vol. 42, no. 4, pp. 367-373, 1995.

[8] S. R. Bowes and P. R. Clark, "Regular-sampled harmonicelimination PWM control of inverter drives," IEEE Transactions on Power Electronics, vol. 10, no. 5, pp. 521-531, 1995.

[9] B. Diong, K. Corzine, S. Basireddy et al., "Multilevel inverterbased dual-frequency power supply," IEEE Power Electronics Letters, vol. 1, no. 4, pp. 115-119, 2003.

[10] R. Salehi, B. Vahidi, N. Farokhnia, and M. Abedi, "Harmonic elimination and optimization of stepped voltage of multilevel inverter by bacterial foraging algorithm," Journal of Electrical Engineering and Technology, vol. 5, no. 4, pp. 545-551, 2010.

[11] M. H. Etesami, N. Farokhnia, and S. H. Fathi, "Colonial competitive algorithm development toward harmonic minimization in multilevel inverters," IEEE Transactions on Industrial Informatics, vol. 11, no. 2, pp. 459-466, 2015.

[12] J. Cheng, D. Chen, and G. Chen, "Modeling and compensation for dead-time effect in high power IGBT/IGCT converters with SHE-PWM modulation," Energies, vol. 13, no. 17, p. $4348,2020$.

[13] H. S. Patel and R. G. Hoft, "Generalized techniques of harmonic elimination and voltage control in thyristor inverters: part I-harmonic elimination," IEEE Transactions on Industry Applications, vol. IA-9, no. 3, pp. 310-317, 1973.

[14] H. S. Patel and R. G. Hoft, "Generalized techniques of harmonic elimination and voltage control in thyristor inverters: part II-voltage control techniques," IEEE Transactions on Industry Applications, vol. IA-10, no. 5, pp. 666-673, 1974.

[15] S. Marcin, J. Włodzimierz, and S. Adam, "Application of grasshopper optimization algorithm for selective harmonics elimination in low-frequency voltage source inverter," Energies, vol. 13, no. 23, p. 6426, 2020.

[16] S. S. Lee, B. Chu, N. R. N. Idris, H. H. Goh, and Y. E. Heng, "Switched-battery boost-multilevel inverter with GA optimized SHEPWM for standalone application," IEEE Transactions on Industrial Electronics, vol. 63, no. 4, pp. 2133-2142, 2016.

[17] A. Kavousi, B. Vahidi, R. Salehi, M. K. Bakhshizadeh, N. Farokhnia, and S. H. Fathi, "Application of the bee algorithm for selective harmonic elimination strategy in multilevel inverters," IEEE Transactions on Power Electronics, vol. 27, no. 4, pp. 1689-1696, 2012.

[18] M. Balasubramonian and V. Rajamani, "Design and real-time implementation of SHEPWM in single-phase inverter using generalized Hopfield neural network," IEEE Transactions on Industrial Electronics, vol. 61, no. 11, pp. 6327-6336, 2014.

[19] L. Gao, S. Yu, H. Zhou, C. Liu, N. Chen, and Y. Huang, "Depth-focused waveform based on SHEPWM method for ground-airborne frequency-domain electromagnetic survey," IEEE Journal of Selected Topics in Applied Earth Observations and Remote Sensing, vol. 12, no. 6, pp. 1981-1990, 2019. 